\title{
A SENSITIVITY ANALYSIS AND AN IMPLEMENTATION OF THE WELL- KNOWN VOGEL'S APPROXIMATION METHOD FOR SOLVING UNBALANCED TRANSPORTATION PROBLEM
}

\author{
Z.A.M.S. Juman ${ }^{1 *}$, M.A. Hoque ${ }^{2}$ ， M.I. Buhari ${ }^{3}$ \\ ${ }^{1,2}$ Department of Mathematics, Faculty of Science, University of Brunei Darussalam, Brunei Darussalam. \\ ${ }^{3}$ Department of Information Technology, Faculty of Computing and Information Technology, King Abdul \\ Aziz University, Jeddah, Saudi Arabia. \\ *Corresponding author : jumanabdeen@yahoo.com
}

\begin{abstract}
Though, in the literature, many heuristic approaches were developed in getting an initial solution, VAM (Vogel's approximation method) is considered to be a better efficient heuristic approach since it often provides an optimal or near optimal solution to the transportation problem. In general, transportation problems involved in supply-chain management fields are unbalanced (total supply $>$ total demand or total supply < total demand) and large-scale problem size. Always, an unbalanced transportation problem is balanced before VAM procedure is applied. But, sometimes, using VAM with unbalanced feature can provide an improved VAM solution. To study this, a sensitivity analysis of VAM has been performed. Based on the sensitivity analysis of VAM, we can conclude that when we solve an unbalanced transportation problem using VAM procedure it is vital to solve the unbalanced transportation problem both ways with balancing and without balancing to get the initial costs of VAM and take the better one as the initial cost to the considered unbalanced transportation problem. Further, in solving large-scale transportation problems, an implementation of VAM is preferred due to time-consuming computations of VAM. In this paper, an attempt has been made to implement the coding of VAM successfully using C++ and compared to the existing coding of VAM from Nabendu Sen et al. [12] via many numerical examples. Based on the results of numerical examples, we can conclude that the correctness of the newly coded VAM is promising as compared with the previously coded one by Nabendu Sen et al. [12].
\end{abstract}

Keywords: Transportation problem, Vogel's approximation method, Heuristic approach, Initial solution.

\section{INTRODUCTION}

The transportation problem is a special class of linear programming problem that deals with shipping a product from multiple origins to multiple destinations. The objective of the transportation problem is to find a feasible way of transporting the shipments to meet demand of each destination that minimizes the total transportation cost while satisfying the supply and demand constrains.

Due to time-consuming computations of the simplex method (for more detail, refer to Reeb and Leavengood [1] ), the transportation method is preferred in solving transportation problems. Determination of the initial basic feasible solution (IBFS) and checking its optimality are the two basic steps of the transportation method. That is, all the optimal solution approaches (e.g., stepping stone method - Charnes and cooper [2], modified distribution method - Dantzig [3], etc ) in solving transportation problems need an IBFS to get the optimal solution. Though, in the literature, many heuristic approaches were developed in getting an initial solution, such as Northwest corner method ( Taha Hamdy [4] ), minimum cost method ( Taha Hamdy [4] ), VAM - Vogel's approximation method ( Reinfeld and Vogel [5] ), etc, VAM is considered to be a better heuristic approach. Shweta Singh et al. [6] improved VAM by using total opportunity cost and regarding alternative allocation cost. Goyal [7] improved the VAM procedure for solving unbalanced transportation problems. Saleem and Imad [8] proposed a hybrid two-stage algorithm to find the optimal solution for transportation problem. Edward Samuel [9] improved the zero point method in solving both crisp and fuzzy transportation problems. Susann et al. [10] analyzed degeneracy characterizations for two classical problems. Kulkarni and Datar [11] proposed a heuristic method of obtaining an initial basic feasible solution (IBFS) to solve modified unbalanced transportation problem. Five methods namely northwest corner method, minimum cost method, row minimum cost 
method, column minimum cost method and VAM were coded in $\mathrm{C}++$ by Nabendu Sen et al. [12] for solving transportation problem. We found that the object oriented program of VAM given by Nabendu Sen et al. [12] for solving transportation problem is not correctly coded. This is checked with many randomly generated problem instances and found that his coding worked for none. In this paper the coding of VAM is implemented in $\mathrm{C}++$. Then its correctness is verified via many randomly generated instances. In addition to that a sensitivity analysis has been performed on wellknown VAM procedure to see the influence of balancing and unbalancing issues on the initial cost solution of VAM obtained by solving unbalanced transportation problem.
The remainder of this paper is organized as follows: Section 2 deals with the mathematical formulation of the transportation problem. In section 3 the well-known VAM procedure is summarized. Section 4 deals with sensitivity analysis of VAM. In Section 5 potential significance of the developed object oriented programming of VAM is illustrated with a numerical example. Finally, conclusion by highlighting the limitations and future research scope on the topic is made in section 6.

\section{MATHEMATICAL STATEMENT OF THE TRANSPORTATION PROBLEM}

In developing the LP model of the transportation problem the following notations are used :

$$
\begin{array}{ll}
a_{i} & \text { Amounts to be shipped from shipping origin } i\left(a_{i} \geq 0\right) . \\
b_{j} & \text { Amounts to be received at destination } j\left(b_{j} \geq 0\right) . \\
c_{i, j} & \text { Shipping cost per unit from origin } i \text { to destination } j\left(c_{i, j}>0\right) \\
x_{i, j} & \text { Amounts to be shipped from origin } i \text { to destination } j \text { to minimize the total cost }\left(x_{i, j} \geq 0\right) .
\end{array}
$$

We assume that the total amount shipped is greater than or equal to the total amount received, that is,

$$
\sum_{i=1}^{m} a_{i} \geq \sum_{j=1}^{n} b_{j}
$$

Transportation Problem

$$
\operatorname{Min} \sum_{i=1}^{m} \sum_{j=1}^{n} c_{i j} x_{i j}
$$

Subject to $\sum_{j=1}^{n} x_{i j} \leq a_{i}, \quad i=1,2, \ldots, m$

$$
\sum_{i=1}^{m} x_{i j}=b_{j}, j=1,2, \ldots, n
$$

where $x_{i j} \geq 0 \forall i, j$.

\section{VOGEL'S APPROXIMATION METHOD (VAM)}

The steps involved in VAM in producing the initial feasible solution are described below:

Step 0: Balance the given transportation problem if either (total supply > total demand) or (total supply < total demand).
Step 1: For each row and column of the transportation table, determine the difference between the least and the next least shipping costs.

Step 2: Select the row or column with the largest difference (breaking ties arbitrarily).

Step 3: Assign as many units as possible to the least cost square in the row or column selected.

Step 4: Eliminate any row or column that has completely been satisfied by the assignment just made.

Step 5: Recalculate the cost differences omitting rows or columns already crossed out in the preceding step.

Step 6: Move to step 2 and repeat the steps $2-5$ until an initial feasible solution has been obtained.

\section{SENSITIVITY ANALYSIS}

In General, before VAM procedure is applied to solve the unbalanced transportation problems, 
the problem has to be balanced first by adding a dummy column (if total supply $>$ total demand) or dummy row (if total supply $<$ total demand). In this section, an attempt has been taken to use VAM procedure for solving the unbalanced transportation problem first by balancing and then without balancing it. Following this, we found that in certain circumstances, balancing is a must before VAM procedure is applied for solving unbalanced transportation problems. In contrast, there are also certain circumstances, where balancing not to be done before VAM is applied. This is illustrated by following two unbalanced transportation problems taken from previous journal papers.

\section{Problem 1}

The following 5 x 4 numerical problem from Nabendu Sen et al. [12] is used to illustrate whether balancing a unbalanced transportation problem is vital or not.

Table 1 The cost matrix table of Nabendu Sen et al. [12]

\begin{tabular}{cccccc}
$\begin{array}{c}\text { From / } \\
\text { To }\end{array}$ & $\mathrm{b}_{1}$ & $\mathrm{~b}_{2}$ & $\mathrm{~b}_{3}$ & $\mathrm{~b}_{4}$ & Supply \\
\hline $\mathrm{a}_{1}$ & 60 & 120 & 75 & 180 & 8000 \\
$\mathrm{a}_{2}$ & 58 & 100 & 60 & 165 & 9200 \\
$\mathrm{a}_{3}$ & 62 & 110 & 65 & 170 & 6250 \\
$\mathrm{a}_{4}$ & 65 & 115 & 80 & 175 & 4900 \\
$\mathrm{a}_{5}$ & 70 & 135 & 85 & 195 & 6100 \\
\hline Demand & 5000 & 2000 & 10000 & 6000 & $\mathbf{3 4 , 4 5 0} /$ \\
& & & & & $\mathbf{2 3 , 0 0 0}$ \\
\hline
\end{tabular}

(i) VAM is used after balancing the problem

Table 2 The Balanced cost matrix (by the addition of dummy column b5) for table 1

\begin{tabular}{ccccccc}
\hline $\begin{array}{c}\text { From / } \\
\text { To }\end{array}$ & $\mathrm{b}_{1}$ & $\mathrm{~b}_{2}$ & $\mathrm{~b}_{3}$ & $\mathrm{~b}_{4}$ & $\mathrm{~b}_{5}$ & Supply \\
\hline $\mathrm{a}_{1}$ & 60 & 120 & 75 & 180 & 0 & 8000 \\
$\mathrm{a}_{2}$ & 58 & 100 & 60 & 165 & 0 & 9200 \\
$\mathrm{a}_{3}$ & 62 & 110 & 65 & 170 & 0 & 6250 \\
$\mathrm{a}_{4}$ & 65 & 115 & 80 & 175 & 0 & 4900 \\
$\mathrm{a}_{5}$ & 70 & 135 & 85 & 195 & 0 & 6100 \\
\hline Demand & 5000 & 2000 & 10000 & 6000 & 11450 & $\mathbf{3 4 , 4 5 0} /$ \\
\hline
\end{tabular}

Table 3 The VAM initial cost allocations for the problem from Nabendu Sen et al. [12]

\begin{tabular}{|c|c|c|c|c|c|c|}
\hline $\begin{array}{c}\text { From / } \\
\text { To }\end{array}$ & $\mathbf{b}_{1}$ & $\mathbf{b}_{2}$ & $\mathbf{b}_{3}$ & $\mathbf{b}_{4}$ & $b_{5}$ & Supply \\
\hline \multirow{2}{*}{$\mathbf{a}_{1}$} & 60 & 120 & 75 & 180 & 0 & \\
\hline & 5000 & & 3000 & & & \multirow{2}{*}{8000} \\
\hline \multirow{2}{*}{$\mathbf{a}_{2}$} & 58 & 100 & 60 & 165 & 0 & \\
\hline & & 2000 & 1200 & 6000 & & \multirow{2}{*}{9200} \\
\hline \multirow{2}{*}{$\mathbf{a}_{3}$} & 62 & 110 & 65 & 170 & 0 & \\
\hline & & & 5800 & & 450 & 6250 \\
\hline \multirow{2}{*}{$\mathbf{a}_{4}$} & 65 & 115 & 80 & 175 & 0 & \multirow{3}{*}{4900} \\
\hline & & & & & 4900 & \\
\hline \multirow{2}{*}{$\mathbf{a}_{5}$} & 70 & 135 & 85 & 195 & 0 & \\
\hline & & & & & 6100 & 6100 \\
\hline Demand & 5000 & 2000 & 10000 & 6000 & 11450 & $\begin{array}{c}34,450 / \\
34,450\end{array}$ \\
\hline
\end{tabular}

The associated initial cost for the problem from Nabendu Sen et al. [12] obtained from table 3 is $2,164,000$. It should be noted that in Nabendu Sen et al. [12], for the same problem this cost is $1,273,000$ which is incorrect. This $1,273,000$ should be corrected as 2,164,000. However, the optimal cost for this problem is $2,146,750$.

(ii) VAM is used without balancing the problem

Table 4 The VAM initial cost allocations for the problem from Nabendu Sen et al. [12]

\begin{tabular}{|c|c|c|c|c|c|}
\hline From / To & $b_{1}$ & $\mathbf{b}_{2}$ & $\mathbf{b}_{3}$ & $\mathbf{b}_{4}$ & Supply \\
\hline \multirow{2}{*}{$\mathbf{a}_{1}$} & 60 & 120 & 75 & 180 & \multirow{3}{*}{8000} \\
\hline & 5000 & & 3000 & & \\
\hline \multirow{2}{*}{$\mathbf{a}_{2}$} & 58 & 100 & 60 & 165 & \\
\hline & & 2000 & & & \multirow{2}{*}{9200} \\
\hline \multirow{2}{*}{$\mathbf{a}_{3}$} & 62 & 110 & 65 & 170 & \\
\hline & & & 900 & 1100 & 6250 \\
\hline \multirow{2}{*}{$\mathbf{a}_{4}$} & 65 & 115 & 80 & 175 & \multirow{3}{*}{4900} \\
\hline & & & & 4900 & \\
\hline \multirow[t]{2}{*}{$\mathbf{a}_{5}$} & 70 & 135 & 85 & 195 & \\
\hline & & & 6100 & & 6100 \\
\hline Demand & 5000 & 2000 & 10000 & 6000 & $\begin{array}{c}34,450 / \\
23,000\end{array}$ \\
\hline
\end{tabular}

The associated initial cost for the same problem from Nabendu Sen et al. [12] obtained from table 4 is $2,346,500$. 


\section{Problem 2}

The following $4 \times 3$ numerical problem from Kulkarni \& Datar [11] is used to illustrate whether balancing an unbalanced transportation problem is vital or not.

Table 5 The cost matrix table of Kulkarni \&

\begin{tabular}{ccccc}
\multicolumn{5}{c}{ Datar [11] } \\
$\begin{array}{c}\text { From / } \\
\text { To }\end{array}$ & $\mathbf{b}_{\mathbf{1}}$ & $\mathbf{b}_{\mathbf{2}}$ & $\mathbf{b}_{\mathbf{3}}$ & Supply \\
\hline $\mathbf{a}_{\mathbf{1}}$ & 3 & 4 & 6 & 100 \\
$\mathbf{a}_{2}$ & 7 & 3 & 8 & 80 \\
$\mathbf{a}_{3}$ & 6 & 4 & 5 & 90 \\
$\mathbf{a}_{4}$ & 7 & 5 & 2 & 120 \\
\hline Demand & 110 & 110 & 60 & $\mathbf{3 9 0} / \mathbf{2 8 0}$ \\
\hline
\end{tabular}

\section{(i) VAM is used after balancing the problem}

Table 6 The Balanced cost matrix (by the addition of dummy column b5) for table 5

\begin{tabular}{cccccc}
\hline $\begin{array}{c}\text { From / } \\
\text { To }\end{array}$ & $\mathbf{b}_{\mathbf{1}}$ & $\mathbf{b}_{\mathbf{2}}$ & $\mathbf{b}_{\mathbf{3}}$ & $\mathbf{b}_{\mathbf{4}}$ & Supply \\
\hline $\mathbf{a}_{\mathbf{1}}$ & 3 & 4 & 6 & 0 & \\
$\mathbf{a}_{\mathbf{2}}$ & 7 & 3 & 8 & 0 & 100 \\
$\mathbf{a}_{\mathbf{3}}$ & 6 & 4 & 5 & 0 & 80 \\
$\mathbf{a}_{\mathbf{4}}$ & 7 & 5 & 2 & 0 & 90 \\
\hline Demand & 110 & 110 & 60 & 110 & $\mathbf{3 9 0} / \mathbf{3 9 0}$ \\
\hline
\end{tabular}

Table 7 The VAM initial cost allocations for the problem from Kulkarni \& Datar [11]

\begin{tabular}{|c|c|c|c|c|c|}
\hline $\begin{array}{c}\text { From / } \\
\text { To }\end{array}$ & $\mathbf{b}_{1}$ & $\mathbf{b}_{2}$ & $\mathbf{b}_{3}$ & $\mathbf{b}_{4}$ & Supply \\
\hline $\mathbf{a}_{1}$ & $\begin{array}{l}3 \\
100\end{array}$ & 4 & 6 & 0 & 100 \\
\hline $\mathbf{a}_{2}$ & 7 & $\begin{array}{l}3 \\
80\end{array}$ & 8 & 0 & 80 \\
\hline $\mathbf{a}_{3}$ & 6 & 4 & 5 & $\begin{array}{l}0 \\
90\end{array}$ & 90 \\
\hline $\mathbf{a}_{4}$ & $\begin{array}{l}7 \\
10\end{array}$ & $\begin{array}{l}5 \\
30\end{array}$ & $\begin{array}{l}2 \\
60\end{array}$ & $\begin{array}{l}0 \\
{ }_{20}\end{array}$ & 120 \\
\hline Demand & 110 & 110 & 60 & 110 & $390 / 390$ \\
\hline
\end{tabular}

The associated initial cost for the problem from Kulkarni \& Datar [11] obtained from table 7 is 880 .

(ii) VAM is used without balancing the problem

Table 8 The VAM initial cost allocations for the problem from Kulkarni \& Datar [11]

\begin{tabular}{|c|c|c|c|c|}
\hline $\begin{array}{c}\text { From / } \\
\text { To }\end{array}$ & $\mathbf{b}_{1}$ & $\mathbf{b}_{2}$ & $\mathbf{b}_{3}$ & Supply \\
\hline $\mathbf{a}_{1}$ & 3 & & 6 & \\
\hline $\mathbf{a}_{2}$ & 7 & & 8 & 100 \\
\hline $\mathbf{a}_{3}$ & 6 & & 5 & 80 \\
\hline $\mathbf{a}_{4}$ & $\begin{array}{ll}7 & \\
& 10\end{array}$ & 50 & ${ }^{2} 60$ & 90 \\
\hline Demand & 110 & 110 & 60 & $390 / 280$ \\
\hline
\end{tabular}

The associated initial cost for the same problem from Kulkarni \& Datar [11] obtained from table 8 is 850 .

However, the optimal cost for problem 1 and Problem 2 are 2,146,750 and 840 respectively.

The Figure 1 represents that if problem 1 is balanced before VAM procedure is applied then the initial cost of problem 1 obtained by VAM procedure is much closer to the optimal cost than in case of unbalancing. In contrast, the Figure 2 represents that if problem 2 is balanced before VAM procedure is applied then the initial cost of problem 2 obtained by VAM procedure is much far to the optimal cost than in case of unbalancing. Thus, by balancing problem 1 we can get a better VAM cost solution with less deviation from its optimal cost. In contrast, without balancing problem 2 we can get a better VAM cost solution with less deviation from its optimal cost (see Fig.3 and Table 9). Hence, it is much better to balance the problem 1 and not to balance the problem 2 before VAM procedure is used. Therefore, when we solve an unbalanced transportation problem using VAM procedure it is vital to solve the same unbalanced transportation problem both ways with balancing and without balancing. Since, VAM procedure is coded in $\mathrm{C}++$ this task can be easily done with coded VAM. 
Table 9 The closeness of VAM initial cost to the optimal cost in case of balancing and unbalancing the unbalanced transportation problems

\begin{tabular}{|c|c|c|c|c|c|c|}
\hline \multirow{2}{*}{ Problems } & \multirow{2}{*}{ Authors } & \multicolumn{2}{|c|}{ VAM initial cost } & \multicolumn{2}{|c|}{$\begin{array}{l}\text { Deviation from the } \\
\text { optimal cost }(\%)\end{array}$} & \multirow{2}{*}{ Optimal Cost } \\
\hline & & $\begin{array}{c}\text { By } \\
\text { Balancing }\end{array}$ & $\begin{array}{l}\text { Without } \\
\text { Balancing }\end{array}$ & $\begin{array}{c}\text { VAM cost } \\
\text { by } \\
\text { balancing }\end{array}$ & $\begin{array}{c}\text { VAM cost } \\
\text { without } \\
\text { Balancing }\end{array}$ & \\
\hline 1 & $\begin{array}{c}\text { Nabendu Sen et al. } \\
{[12]}\end{array}$ & $2,164,000$ & $2,346,500$ & 0.80 & 9.30 & $2,146,750$ \\
\hline 2 & $\begin{array}{c}\text { Kulkarni \& Datar } \\
{[11]}\end{array}$ & 880 & 850 & 4.80 & 1.20 & 840 \\
\hline
\end{tabular}

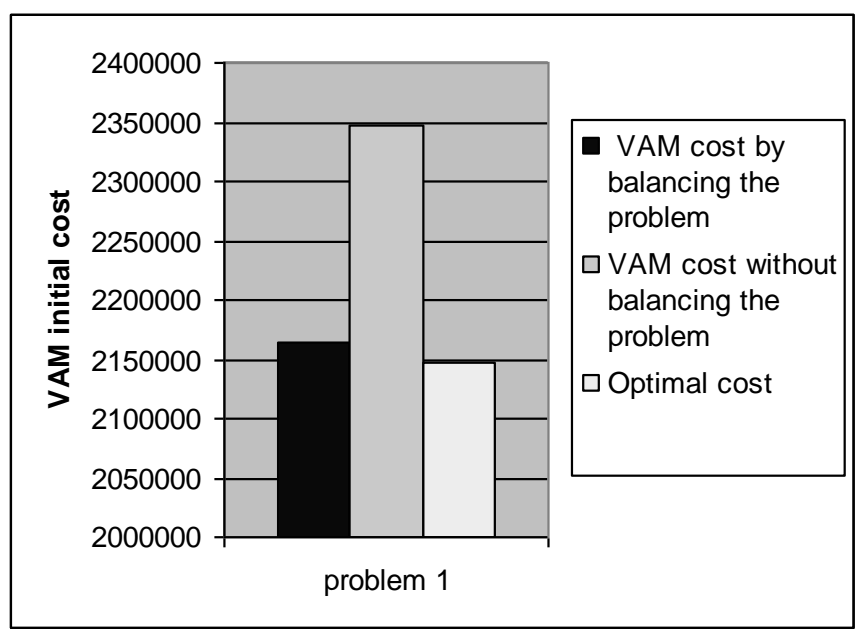

Figure 1 Influence of balancing and unbalancing issues of problem1 on VAM initial cost

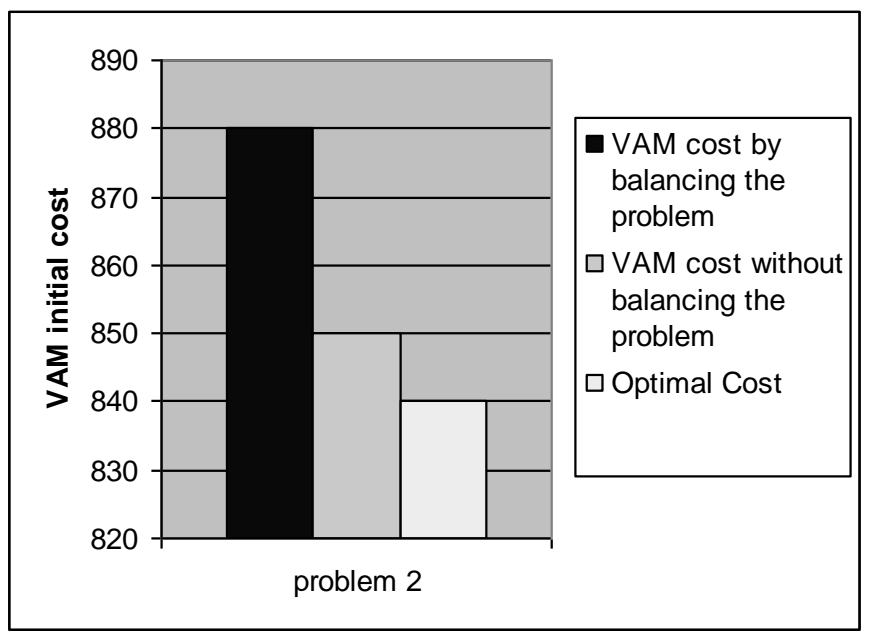

Figure 2 Influence of balancing and unbalancing issues of problem 2 on VAM initial cost

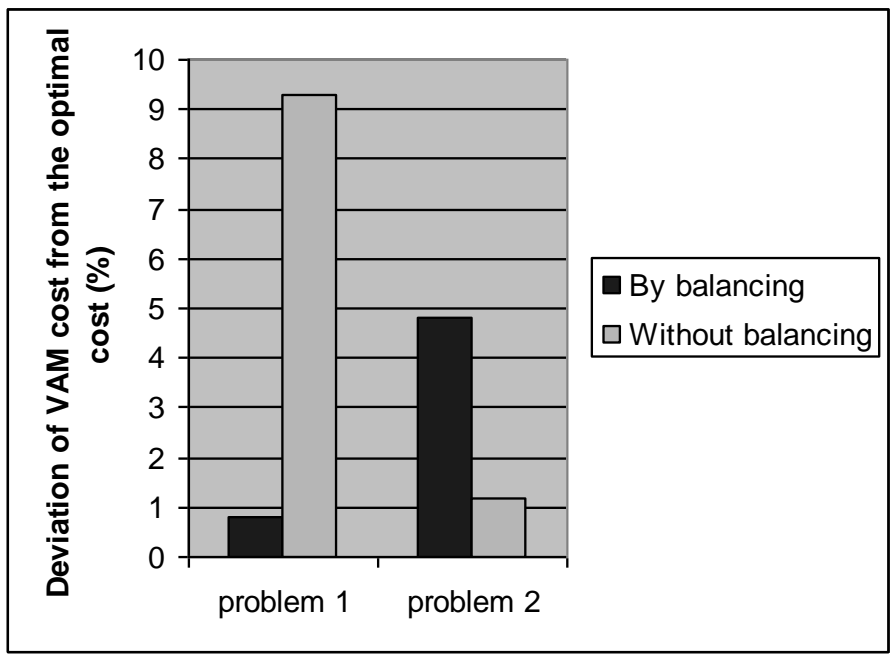

Figure 3 Deviation of VAM cost from the optimal cost for both problems in case of balancing and unbalancing 


\section{NUMERICAL ILLUSTRATION}

The following 6 numerical examples taken from previous papers shown in Table $\mathbf{1 0}$ and the 5 randomly generated ones shown in table $\mathbf{1 1}$ are used to show the potential significant of the developed Object Oriented Programming (ORP) of VAM in this paper.

Table 10 The initial costs of 6 numerical examples obtained using Object Oriented Programming (ORP) of VAM in this paper and in Nabendu Sen et al. [12]

\begin{tabular}{|c|c|c|c|}
\hline \multirow[b]{2}{*}{ Examples } & \multirow[b]{2}{*}{ Authors } & \multicolumn{2}{|c|}{$\begin{array}{c}\text { VAM initial cost } \\
\text { obtained by running } \\
\text { the ORP }\end{array}$} \\
\hline & & $\begin{array}{l}\text { This } \\
\text { Paper }\end{array}$ & $\begin{array}{c}\text { Nabendu } \\
\text { Sen et al. } \\
{[12]}\end{array}$ \\
\hline 1 & $\begin{array}{c}\text { Raeeb, J \& } \\
\text { Leavengood, S. } \\
\text { [1] }\end{array}$ & 4400 & - \\
\hline 2 & $\begin{array}{l}\text { Shweta Singh, } \\
\text { G. C. et al. [6] } \\
\text { Goyal, S.K. [7] }\end{array}$ & 2323 & - \\
\hline 3 & & 1745 & - \\
\hline 4 & $\begin{array}{c}\text { Saleem, Z.R } \\
\text { and Imad, Z.R } \\
{[8]} \\
\text { Edward }\end{array}$ & 5600 & - \\
\hline 5 & $\begin{array}{l}\text { Samuel, A. [9] } \\
\text { Susann Schrenk }\end{array}$ & 28 & - \\
\hline 6 & et al. [10] & 59 & - \\
\hline
\end{tabular}

Table 11 The VAM initial costs of 5 randomly generated examples obtained using Object Oriented Programming (ORP) of VAM in this paper and in Nabendu Sen et al. [12]

\begin{tabular}{|c|c|c|c|}
\hline \multirow{2}{*}{ Examples } & \multirow{2}{*}{$\begin{array}{l}\text { Problem } \\
\text { Size } \\
(\mathbf{m} \times \mathbf{n})\end{array}$} & \multicolumn{2}{|c|}{$\begin{array}{c}\text { VAM initial cost } \\
\text { obtained by running the } \\
\text { ORP }\end{array}$} \\
\hline & & This Paper & $\begin{array}{c}\text { Nabendu } \\
\text { Sen et al. } \\
\text { [12] }\end{array}$ \\
\hline 1 & $5 \times 10$ & 31,160 & - \\
\hline 2 & $5 \times 10$ & 3541 & - \\
\hline 3 & $10 \times 15$ & 1669 & - \\
\hline 4 & $10 \times 20$ & 878493 & - \\
\hline 5 & $10 \times 20$ & 4836 & - \\
\hline
\end{tabular}

Both Tables $10 \& \mathbf{1 1}$ represent that the developed Object Oriented Programming of
VAM (coded VAM) in this paper worked for all the examples considered. In contrast, the Object Oriented Programming of VAM proposed by Nabendu Sen et al. [12] worked for none of the example considered in table 10 and table 11 . That is, if we use the coded VAM of Nabendu Sen et al. [12] then we will not be able to get any solution for the examples from table 10 and table 11. In addition to this, Both our coded VAM and the coded VAM of Nabendu Sen et al. [12] were tested with many other examples and found that even though our one give the exact VAM solutions, Nabendu Sen et al. [12] does not. Due to space consideration, the detail of the all five randomly generated examples and the developed object oriented programming of well-known VAM (our coded VAM) for solving transportation problems are not given in this paper and are available from the author.

\section{CONCLUSION}

In this paper, the coding of well-known VAM is successfully implemented using $\mathrm{C}++$ and its correctness is tested via many randomly generated problem instances and six numerical examples taken from previous papers. Based on these results we can conclude that the correctness of the newly coded VAM is promising as compared with the previously coded one by Nabendu Sen et al. [12]. Moreover, a sensitivity analysis has been performed on VAM procedure to see the influence of balancing and unbalancing issues on the initial cost of VAM. We found in certain circumstance, the obtained initial solution by VAM via balancing can be improved if no balancing is done on the unbalanced problem before using VAM. In contrast, we found in the other certain circumstance, the obtained initial solution by VAM via unbalancing can be improved if balancing is done on the unbalanced problem before using VAM. Therefore, when we solve an unbalanced transportation problem using VAM procedure it is vital to solve the same unbalanced transportation problem in both ways with balancing and without balancing. Then by comparing initial cost of VAM obtained in both ways, we can take the better one as the initial cost to the considered unbalanced transportation problem. Since, VAM procedure is coded in C++ this task can be easily done with coded VAM of this paper. Future research might be carried out in proposing an efficient better solution procedure which can provide a better initial solution than VAM for solving 
transportation problems. We intend to devote ourselves in this direction.

\section{ACKNOWLEDGMENT}

The first author sincerely thanks the University Brunei Darussalam (UBD) for supporting his work by a fellowship (GRS) within the Doctoral Program.

\section{REFERENCES}

1. Reeb, J.E. and Leavengood, S.A. (2002). Transportation problem: a special case for linear programming problems. EM8779. Corvallis: Oregon State University Extension Service. 135 .

2. Charnes, A. and Cooper, W.W. (1954). The stepping stone method of explaining linear programming calculations in transportation problems. Management Science. 1(1), 49-69.

3. Dantzig, G.B. (1963). Linear Programming and extensions. Princeton, NJ: Princeton University press.

4. Taha Hamdy A. (2006) Operation Research: An introduction. $8^{\text {th }}$ edition. Prentice-Hall of India.

5. Reinfeld, N.V. and Vogel, W.R. (1958). Mathematical Programming. Englewood Cliffs, New Jersey: prentice-Hall. $\quad 59-70$

6. Shweta Singh et al. (2012). Optimization and analysis of some variants through Vogel's approximation method (VAM). IOSR Journal of Engineering. 2(9), 20-30

7. Goyal, S.K. (1984). Improving VAM for unbalanced transportation problems. Journal of Operational Research Society. $\quad 35(12), \quad$ 1113-1114.

8. Saleem, Z.R. and Imad, Z.R. (2012). Hybrid two-stage algorithm for solving transportation problem. Modern Applied Science. 6(4), 12-22.
9. Edward Samuel A. (2012). Improved zero point method (IZPM) for the transportation problems. Applied Mathematical Sciences. 6(109), 54215426.

10. Susann schrenk et al. (2011). Two classical transportation problems revisited: Pure constant fixed charges and the paradox. Mathematical and Computer Modeling. 54, 2306-2315.

11. Kulkarni, S. S. and Datar, H. G. (2010). On solution to modified unbalanced transportation problem. Bulletin of the Marathwada Mathematical Society. 11(2), 20-26.

12. Nabendu Sen et al. (2010). A study of transportation problem for an essential item of southern part of north eastern region of India as an OR model and use of object oriented programming. International Journal of Computer Science and Network Security. 10(4), 78-86. 